\title{
Benzimidazole: A short review of their antimicrobial activities
}

\author{
*Namrata Singh, Annamalai Pandurangan, Kavita Rana, Preeti Anand, Arsad Ahamad, Amit Kumar Tiwari \\ Bharat Institute of Technology, School of Pharmacy, Bypass Road, Partapur, Meerut, Uttar Pradesh, India
}

\begin{abstract}
Benzimidazole is the heterocyclic compound formed from benzene and imidazole ring containing nitrogen, oxygen sulphor and its derivatives are of wide interest because of their diverse biological activity and clinical applications, they are remarkably effective compounds both with respect to their inhibitory activity and their favourable selectivity ratio. Reported nucleus is a constituent of vitamin-B12. Benzimidazoles are regarded as a promising class of bioactive heterocyclic compounds that exhibit a range of biological activities like anti-microbial, anti-viral, anti-diabetic, anticancer activity, numerous anti-oxidant, anti-parasitic, anti-helmintics, anti-proliferative, anti-HIV, anti-convulsant, anti-inflammatory, anti-hypertensive, anti-neoplastic, proton pump inhibitor and anti-trichinellosis. Benzimidazoles exhibit significant activity as potential antitumor agents, smooth muscle cell proliferation inhibitors, a treatment for intestinal cystitis, and in diverse area of chemistry. Some of the important benzimidazole derivatives have been reported as thyroid receptor agonist gonadotropin releasing hormone receptor antagonists, non-nucleoside HIV-1 reverse transcriptase inhibitors and interestingly alkynylbenzimidazoles as modulators of metabotropic glutamate receptors. The imidazole core is a common moiety in a large number of natural products and pharmacologically active compounds. The synthesis of novel benzimidazole derivatives remains a main focus of medicinal research. This comprehensive overview summarizes the chemistry of different derivative of substituted benzimidazole along with their anti-microbial activity containing anti-malarial anti-fungal, anti-bacterial, anti-viral activities.
\end{abstract}

Key Words: benzimidazoles, anti-malarial, anti-fungal, anti-bacterial, anti-viral.

\section{INTRODUCTION}

Benzimidazole derivatives are of wide interest because of their diverse biological activity and clinical applications, they are remarkably effective compounds both with respect to their inhibitory activity and their favorable selectivity ratio (Ansari et al., 2009, Kazimierczuk et al., 2002, Grocer et al., 2002). Looking at the importance of benzimidazole and oxadiazole nucleus, it was thought that it would be worthwhile to design and synthesize some new benzimidazole derivatives bearing oxadiazole moiety and screen them for potential biological activities. We have previously reported the synthesis of some new biologically active benzimidazoles. Resistance to number of anti-microbial agents $(\beta$ lactam antibiotics, macrolides, quinolones, and

\footnotetext{
*Corresponding Author:

Namrata Singh

Bharat Institute of Technology

School of Pharmacy, Bypass Road, Partapur,

Meerut, Uttar Pradesh, India

E-mail: namrata.pharma85@gmail.com

Contact No.: 8881544437
}

vancomycin) among a variety of clinically significant species of bacteria is becoming increasingly important global problem. In particular, increasing drug resistance among Gram-positive a bacterium such as staphylococci, enterococci, and streptococci is a significant health matter. Benzimidazole ring displays an important heterocyclic pharmacophor in drug discovery. These compounds carrying different substituent's in the benzimidazole structure are associated with a wide range of biological activities including anti-cancer, anti-viral, anti-bacterial, antifungal, anti-helmintic, anti-inflammatory, antihistaminic, proton pump inhibitor, anti-oxidant, Anti-hypertensive and anti-coagulant properties (Tuncbilek et al., 2009). In 1960, Fort et al. reported the discovery of benzimidazole derivatives as proton pump inhibitors. Further, synthesis and evaluation of different substituted benzimidazole derivatives resulted in the discovery of omeprazole, lansoprazole, rabeprazole, and pantoprazole (Figure 1) (Patil et al., 2008). 
The benzimidazole ring is an important pharmacophor in modern drug discovery. In recent years, attention has increasingly been given to the synthesis of benzimidazole derivatives. The synthesis of novel benzimidazole derivatives remains a main focus of medicinal research. Recent observations suggest that substituted benzimidazoles and heterocyclic, show easy interactions with the biopolymers, possess potential activity with lower toxicities in the chemotherapeutic approach in man (Haugwitz et al., 1982).

\section{BIOLOGICAL ACTIVITY OF BENZIMIDAZOLE}

\section{Antimalarial activity}

Malaria caused 350-500 million clinical episodes annually and result in over one million deaths, most of which affect children under 5 years old in sub Saharan Africa. Malaria is the fifth cause of death from infectious diseases worldwide (after respiratory infections, HIV/AIDS, diarrhoeal diseases and tuberculosis). Recent estimates so that as many as 3.3 billion people live in areas at risk of malaria in 109 countries. In addition to its health toll, malaria puts a heavy economic burden on endemic countries and contributes to the cycle of poverty people face in many countries. Malaria mortality and morbidity began to increase in the 1980s due to a combination of factors such as increase in parasite and vector resistance to the current anti-malarial drugs and insecticides, the weakening of traditional malaria control programs, rapid decentralization and integration into deteriorating primary health service, and the development of humanitarian crisis situations in many malaria-endemic areas. This dramatic increase led to a compelling and urgent necessity for new malarial, with mechanisms of action different from the existing ones, and to identify new drug targets. Cloroquine has recently been shown to inhibit hemozoin formation within the parasite food vacuole. This process is also thought to be the molecular target of other quinoline anti-malarial. Hemozoin was originally considered to be formed by the polymerization of heme, but has now been demonstrated to be a crystalline cyclic dimmer of ferriprotoporphyrin IX. Thus, hemozoin synthesis, a process unique to the malaria parasite, offers a logical and valuable potential target for new anti-malarial drug development. New drugs that attack the same vital target of chloroquine but that are not subject to the same resistance mechanism would be highly desirable (Camacho et al., 2011).

Ryckebusch et al. (2005) reported the synthesis of the activity of new N1-(7-chloro-4-quinolyl)-1, 4-bis (3aminopropyl) piperazine derivatives against a chloroquine-resistant strain of Plasmodium falciparum in which compound 1 is active showing best anti-malarial activity. Camacho et al. (2011) reported a series of N-substituted-2-(5-nitrofuran or 5nitrothiophen-2- yl)-3H-benzo[d]imidazole-5carbohydrazide derivatives and screened for their anti-malarial efficacy in rodent Plasmodium berghei. Gomez et al. (2008) reported a series of ten novel hybrids from benzimidazole tested in vitro against the protozoa Trichomonas virginal's, Giardia lamblia, Entamoeba histolytica, Leishmania mexicana, and Plasmodium berghei showed good anti-malarial activity. Vázquez et al. (2006) substituted a series of 2-(trifluoromethyl)-1H-Benzimidazole derivatives and shows good anti-malarial activity. Olmo et al. (2011) reported synthesis of several series of imidazo [2, 1-a] isoindol-5-ol derivatives and evaluated against Plasmodium falciparum.

\section{Antifungal activity}

Infectious diseases have been serious and growing threatens to human health during the past few decades. The decrease of sensibility to anti-microbial agents in current use has also been increasing for a great variety of pathogens and the resistance to multiple drugs is more and more prevalent for several microorganisms, especially for Grampositive bacteria and some intractable fungi. Their inhibitory properties as regard representative fungi have been extensively exploited. Especially, it is worthy to note that Fluconazole, the first -line triazole-anti-fungal drug Recommended by World Health Organization (WHO) has established an exceptional therapeutic record for Candida infections, and become the first choice in the treatment of infections by Candida albicans and Cryptococcus neoformans due to its potent activity, excellent safety profile, and favorable pharmacokinetic characteristics. However, Fluconazole is not effective against invasive aspergillosis and is not fungicidal. In addition, extensive clinical use of Fluconazole has resulted in the increasing Fluconazole- resistant C. albicans isolates (Fang et al., 2010). 
Figure 1: Structures of some established benzimidazole derivatives as antiulcer agents.

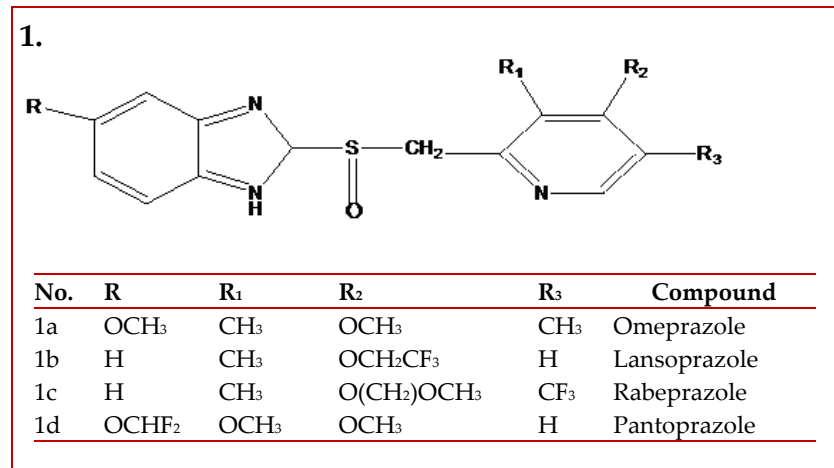

2.

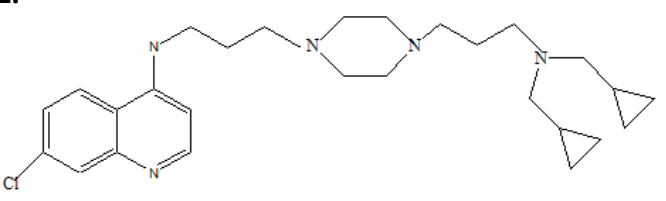

\begin{tabular}{lll}
\hline No. & N & X \\
\hline $2 \mathrm{a}$ & 0 & cyclopropyl \\
$2 \mathrm{~b}$ & 3 & CN \\
$2 \mathrm{c}$ & 2 & NHBoc \\
\hline
\end{tabular}

3.

4.
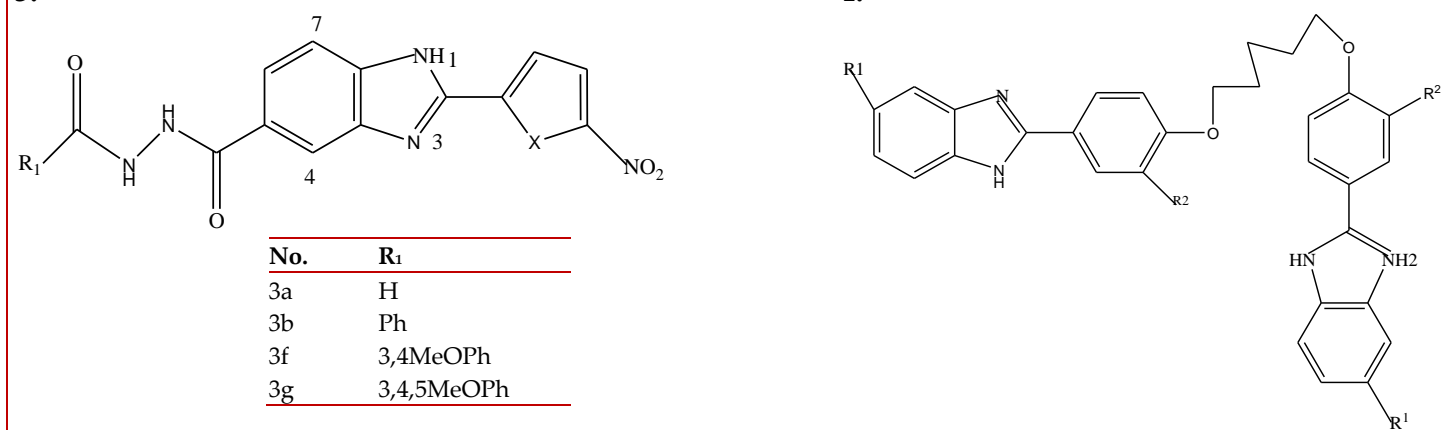

\begin{tabular}{lll}
\hline No. & $\mathbf{R}^{1}$ & $\mathbf{R}^{2}$ \\
\hline 4a & $\mathrm{H}$ & $\mathrm{H}$ \\
4b & $\mathrm{OCH}_{3}$ & $\mathrm{H}$ \\
4c & $\mathrm{CH}_{3}$ & $\mathrm{H}$ \\
4d & $\mathrm{OCH}_{3}$ & $\mathrm{OCH}_{3}$ \\
\hline
\end{tabular}

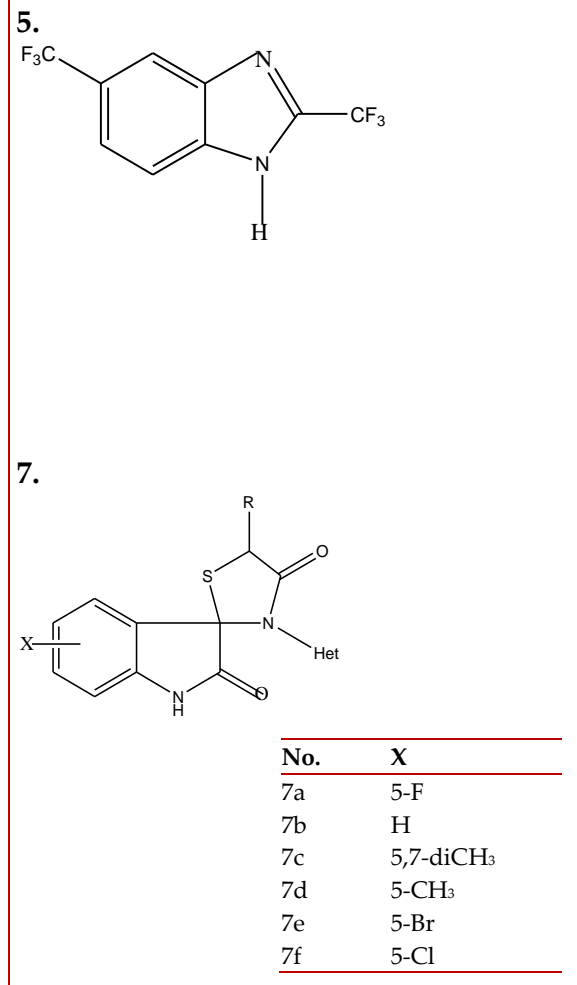

6.

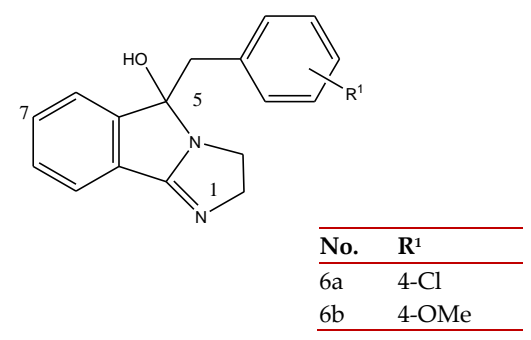

8.

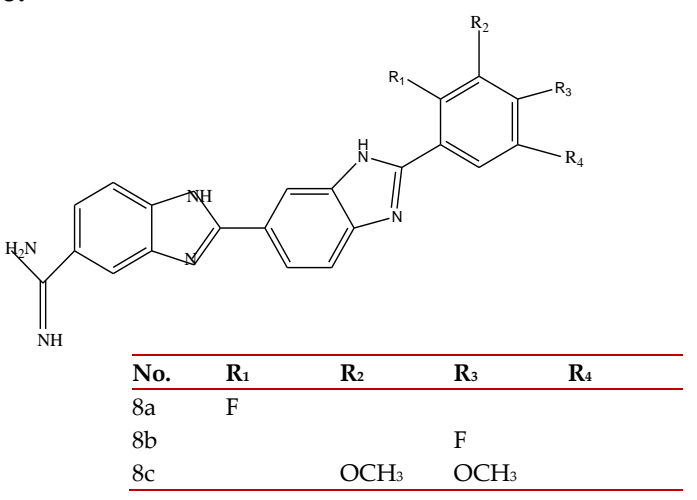

Continued..... 
9.

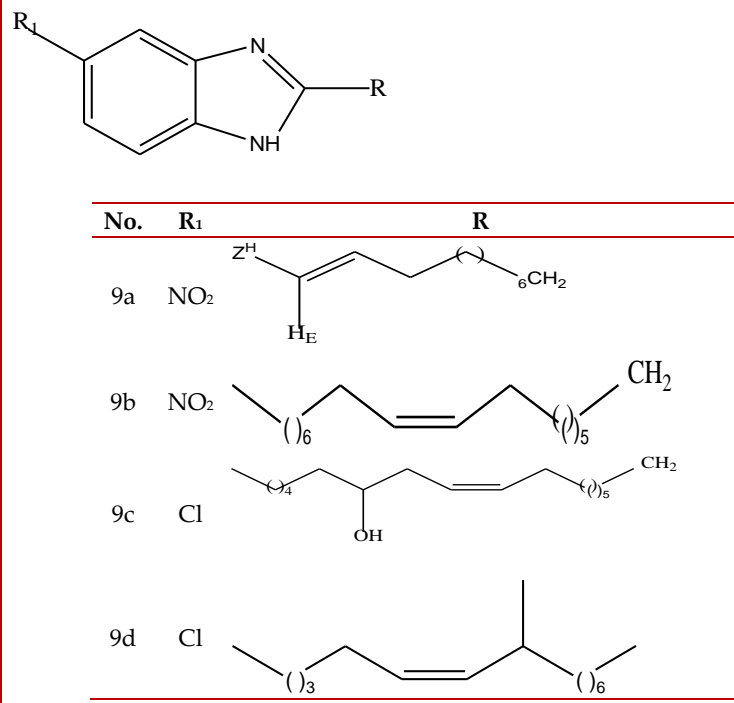

11.

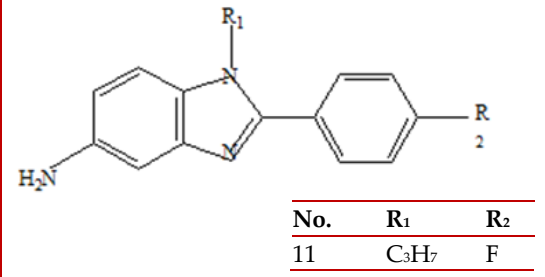

10.

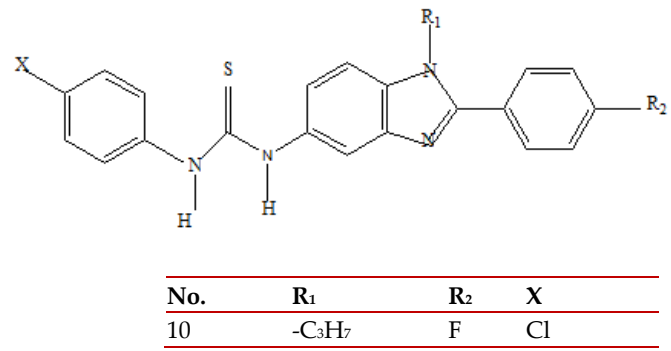

12.<smiles>[R1]c1nc2ccccc2n1[R6]</smiles>

13.

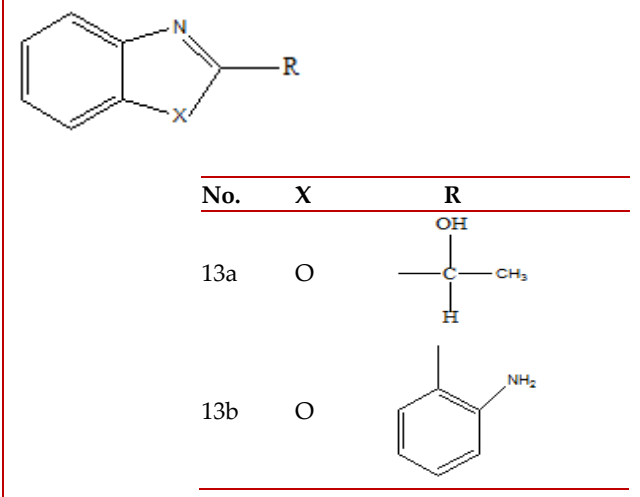

14.

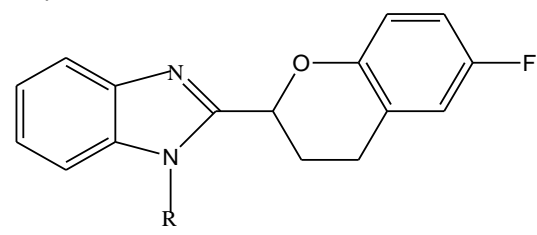

\begin{tabular}{llll}
\hline No. & $\mathbf{R}$ & No. & $\mathbf{R}$ \\
\hline $14 \mathrm{a}$ & Methyl & $14 \mathrm{~h}$ & $-\mathrm{SO}_{2}-\mathrm{CF}_{3}$ \\
$14 \mathrm{~b}$ & Ethyl & $14 \mathrm{i}$ & $-\mathrm{SO}_{2}-\mathrm{Phenyl}$ \\
$14 \mathrm{c}$ & Propyl & $14 \mathrm{j}$ & $-\mathrm{SO}_{2}-\mathrm{C}_{6} \mathrm{H}_{4}-\mathrm{Me}-p$ \\
$14 \mathrm{~d}$ & $n$-Butyl & $14 \mathrm{k}$ & $-\mathrm{Benzyl}^{-}$ \\
$14 \mathrm{e}$ & - CO-O-Ethyl & $14 \mathrm{l}$ & $\mathrm{p}$-Flurobenzyl \\
$14 \mathrm{f}$ & - CO-O-tert Butyl & $14 \mathrm{~m}$ & $p$-Bromobenzyl \\
$14 \mathrm{~g}$ & - CO-Phenyl & $14 \mathrm{n}$ & $p$-Methylbenzyl \\
& & $14 \mathrm{o}$ & $p$-tert-Butylbenzyl \\
\hline
\end{tabular}

Continued..... 


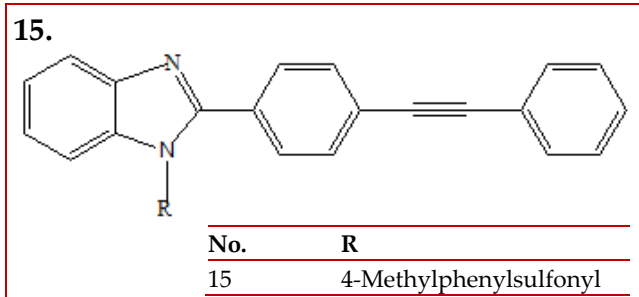

17.

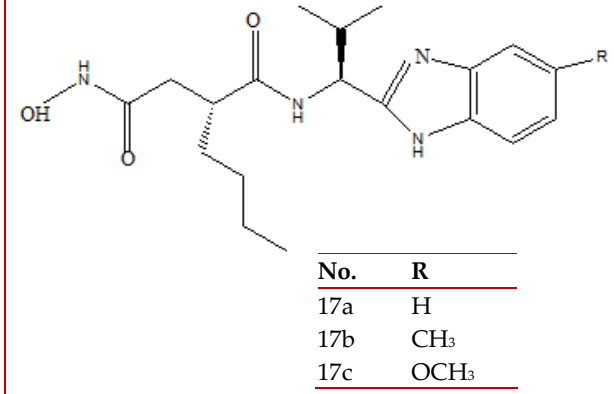

19.

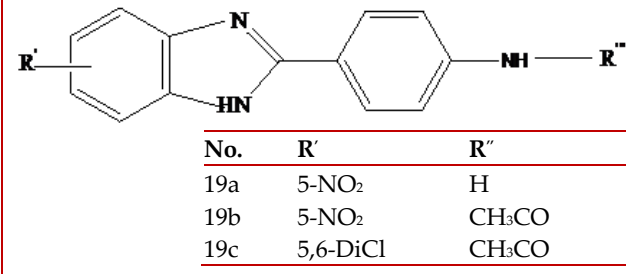

21.

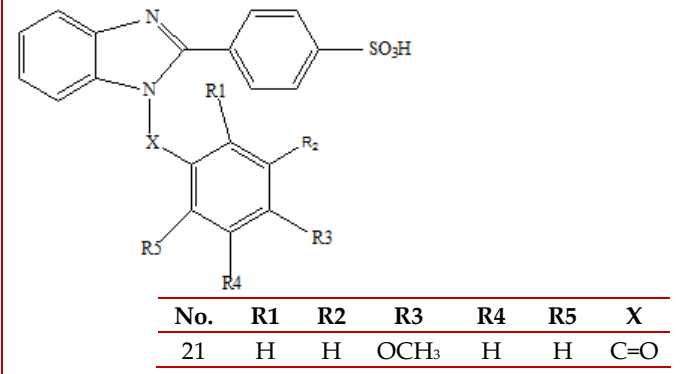

16.

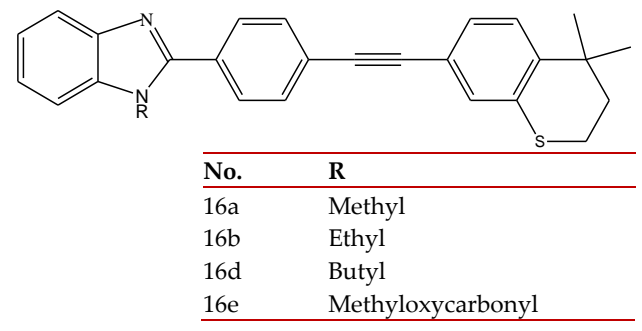

18.

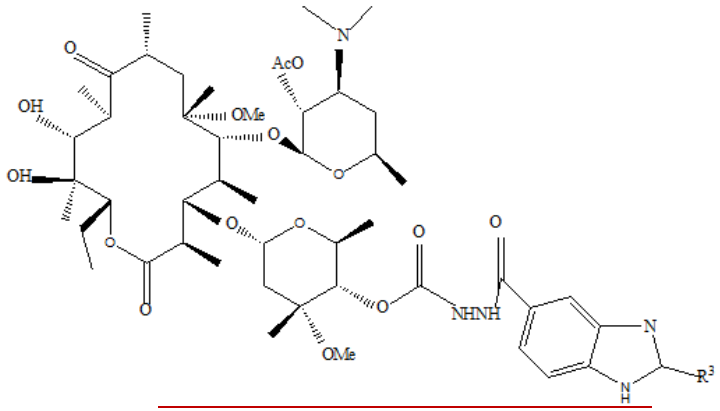

\begin{tabular}{ll}
\hline No. & $\mathbf{R}^{3}$ \\
\hline 18a & Phenyl \\
18b & 2-methoxyphenyl \\
18c & 3-methoxyphenyl \\
18d & 2-chlorophenyl \\
18e & 3-chloro-2-hydroxyphenyl \\
\hline
\end{tabular}

20.

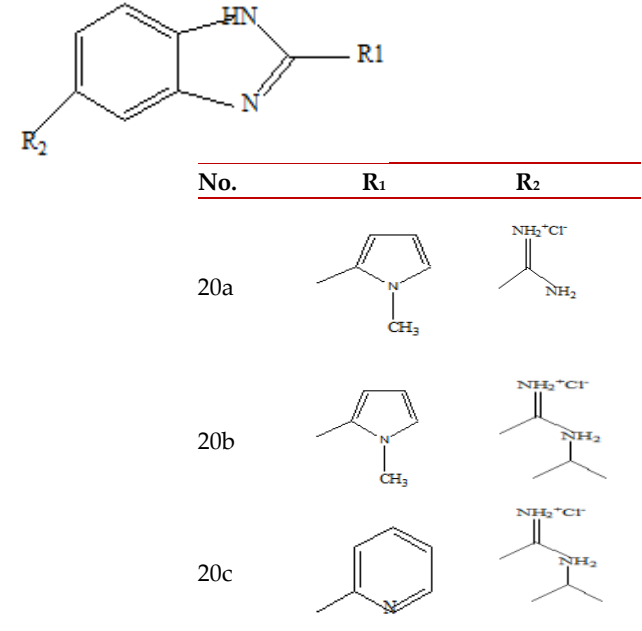

22.

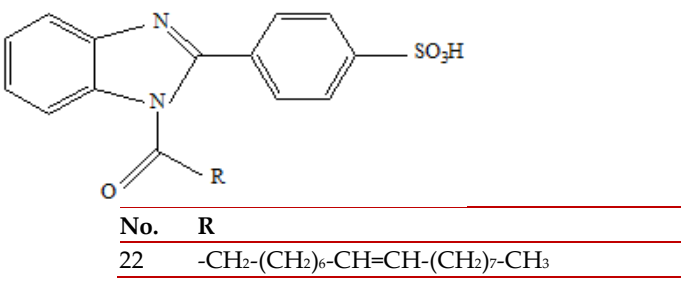

Continued..... 
23.

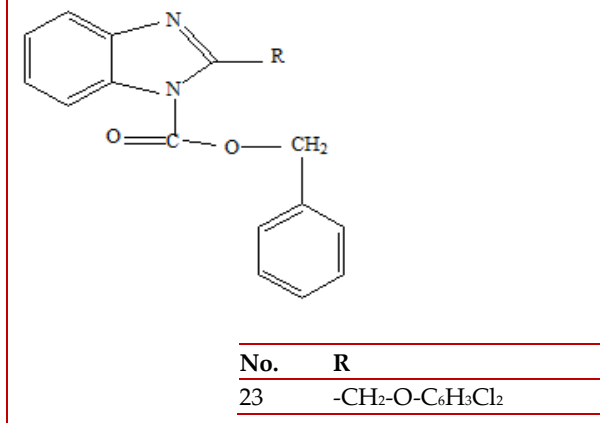

25.
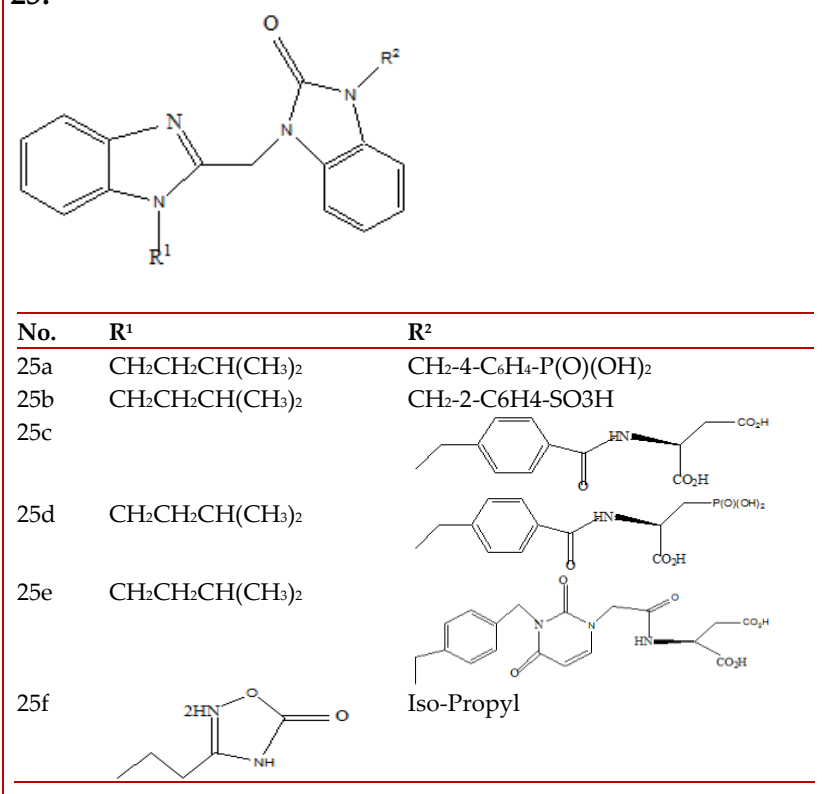

24.

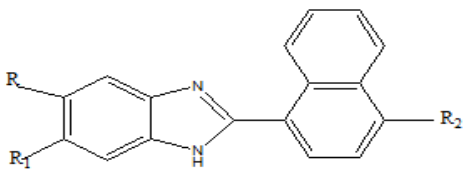

\begin{tabular}{llll}
\hline No. & $\mathbf{R}$ & $\mathbf{R}_{1}$ & $\mathbf{R}_{\mathbf{2}}$ \\
\hline $24 \mathrm{a}$ & $\mathrm{CH}_{3}$ & $\mathrm{CH}_{3}$ & $\mathrm{H}$ \\
$24 \mathrm{~b}$ & $\mathrm{Cl}$ & $\mathrm{H}$ & $\mathrm{NH}_{2}$ \\
$24 \mathrm{c}$ & $\mathrm{Cl}$ & $\mathrm{Cl}$ & $\mathrm{NH}_{2}$ \\
\hline
\end{tabular}

26.
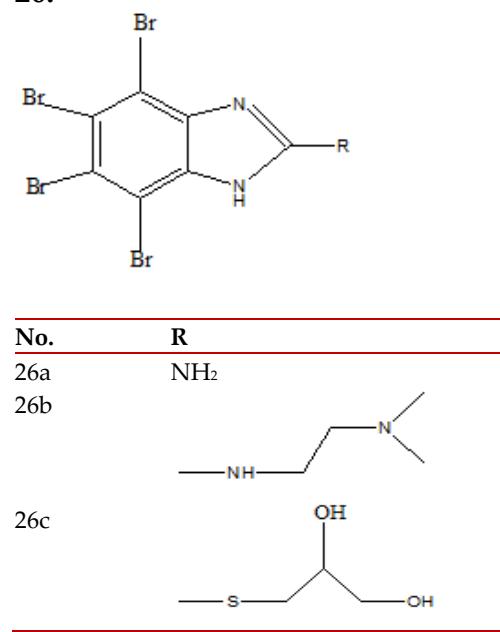

Dandia et al. (2006) reported synthesis of a series of novel spiro [indole-thiazolidinones and screened in vitro for anti-fungal activity against Rhizoctonia solani, Fusarium oxysporum and Collectotrichum. Alp et al. (2009) reported synthesis of series of 20arylsubstituted-1H, 10H-[2, 50] - bisbenzimidazolyl5-carboxamidines and evaluated for their antifungal activity. Sharma et al. (2009) reported synthesis of a series of novel 2-substituted benzimidazoles, tetrahydrobenzimidazoles and imidazoles and screened there in vitro anti-bacterial anti-fungal activities. Kilcigil et al. (2006) reported synthesis of a series of novel benzimidazole derivatives and evaluated for anti-fungal activity. Cvetkovic et al. (2011) reported Lipophilicity and anti-fungal activity of some 2-substituted benzimidazole derivatives against yeast Saccharomyces cerevisiae. Elnima et al. (1981) reported for Anti-bacterial and Anti-fungal Activities of Benzimidazole and Benzo- xazole Derivatives against standard strains and 59 clinical Isolate and compound $13 \mathrm{a}$ and $13 \mathrm{~b}$ is active.

\section{Antibacterial activity}

The increase in bacterial resistance has attracted considerable interest in the discovery and development of new classes of anti-bacterial agents. The new agents should preferably consist of chemical characteristics that clearly differ from those of existing agents. Actinonin was first isolated from a Malayan strain of Actinomyces and found to show a weak inhibitory activity against Gram-positive and Gram-negative bacteria. However, recently actinonin has been proven to have anti-proliferative effects on human tumor cells. The action mechanism of actinonin is believed to be the inhibition of the peptide deformylase that is a new class of metalloenzyme which is essential for bacterial survival. The hydroxamate group of actinonin, which can 
complex with the metal ion in the active pocket of the peptide deformylase, is necessary for its activity. Nevertheless, actinonin lacks in vivo efficacy, due to the poor bioavailability (Zhang et al., 2009). Secondgeneration macrolides such as clarithromycin (CAM) and azithromycin (AZM) (Figure 1) have enjoyed widespread clinical use for the treatment of upper and lower respiratory tract infections as well as genital infections due to their superior antibacterial activity, pharmacokinetic properties and fewer gastrointestinal side (GI) effects compared with first-generation macrolides such as erythromycin (EMA) which is its acid instability, leading to consequential degradation products responsible for its poor pharmacokinetic profile and GI side effects . Their mechanism of action has been elucidated that the macrolides bind reversibly to the nucleotide A2058 in domain V of the 23S rRNA in the ribosomal $50 S$ subunit and block protein synthesis. However, the therapeutic Utility of the macrolides has been severely compromised by the emergence of widespread bacterial resistance which has become a serious medical problem worldwide. The predominant mechanism of resistance involves the methylation of A2058 by a ribosomal methylase encoded by the erm gene, which confers a high level of resistance to MLSB (macrolide-lincosamidestreptogramin B) antibiotics. Third-generation macrolides known as ketolides such as telithromycin and cethromycin were developed to overcome erm- resistant bacteria through interacting with a secondary ribosomal binding site A752 directly in domain II of the $23 \mathrm{~S}$ rRNA by their C-11-12 carbamate or C-6 side chains in addition to the main interaction of the drugs in domain V (Cong et al., 2011).

Kumar et al. (2006) reported synthesis of some novel 2-(6-fluorochroman-2-yl)-1-alkyl/acyl/aroyl-1Hbenzimidazoles and compounds exhibited promising anti-bacterial activity against Salmonella typhimurium. Kumar et al. (2008) reported synthesis of a series of novel and functionalized benzimidazole derivatives by the condensation of OPDA with 4-bromobenzoic acid and screened for their potential anti-bacterial. Zhang et al. (2009) reported synthesis of a series of novel actinonin derivatives containing a benzimidazole heterocyclic linked as amide isostere and evaluated in vitro against Staphylococcus aureous, Klebsiella pneumonia, and Sarcina lutea. Cong et al. (2011) reported synthesis of Novel 400-O-benzimidazolyl clarithromycin derivatives \& evaluated for their in vitro anti-bacterial activities.

\section{Antiviral activity}

Chronic infection with the hepatitis $\mathrm{C}$ virus (HCV) is a major risk factor for developing cirrhosis and hepatocellular carcinoma. Approximately 3\% of the worldwide population is chronically infected with HCV (Alter and Seeff, 2000; Bialek and Terrault, 2006). A preventive vaccine has not been developed and limits of current therapeutics include serious side effects and therapy usually lasting 48 weeks with only a $50 \%$ sustained virological response rate (Bowen and Walker, 2005; De Francesco and Migliaccio, 2005; Fried et al., 2002; Houghton and Abrignani, 2005). A recent major advance was the development of an infectious virus system based on the transfection of human hepatoma cells with genomic HCV RNA (JFH1) isolated from a patient with fulminant hepatitis (Kato et al., 2001; Lindenbach et al., 2005; Wakita et al., 2005; Zhong et al., 2005). This cell culture model allows all stages of the HCV life cycle to be studied (Liu et al., 2011). Antiviral properties of various benzimidazole derivatives have been reported in a variety of studies using different virus strains, such as human cytomegalovirus (HCMV), human immunodeficiency virus, and hepatitis B and C virus. Also, amidinosubstituted benzimidazoles, such as bis(5-amidino2-benzimidazolyl) methane (BABIM), showed ability to block respiratory syncytial (RS) virus induced cell fusion. In addition, introducing amidino moiety to benzimidazole ring was shown to possess potent antimicrobial and anti-protozoal activity.

Liu et al. (2011) reported Major progress has been made in developing infectious HCV cell culture systems and these systems have been useful in identifying novel HCV anti-viral. Starcevic et al. (2007) prepared a set of heterocyclic benzimidazole derivatives bearing amidino substituent at C-5 of benzimidazole ring, by introducing various heterocyclic nuclei (pyridine, N-methyl-pyrrole or imidazole) at C-2, and evaluated their anti-tumor and anti-viral activities. Yadav et al. (2010) reported synthesis of a series of 4-[1-(substituted aryl/alkyl carbonyl)-benzoimidazol-2-yl]-benzene sulphonic acids and evaluated for anti-fungal activity and 
compounds 4-[1-(4-Nitrobenzoyl)-1H-benzoimidazol-2-yl] benzenesulfonic acid and 4-(1-octadec-9enoyl-1H-benzoimidazol-2-yl)-benzenesulfonic acid was found to be the most active ones. Gupta et al. (2010) reported synthesis of benzimidazoles by refluxing o-phenyldiamine with corresponding carbo-xylic acids and evaluated for anti-viral activity against PRSV on plant chenopodiun amranticular. Vitale et al. (2008) reported a new series of 2arylbenzimidazoles and evaluated them for antiviral activity as well as anti-proliferative. Compounds were tested in cell-based assays against viruses' representative of: i) two of the three genera of the Flaviviridae family, i.e. Flaviviruses and Pestiviruses; ii) other RNA virus families, such as Retroviridae, Picornaviridae, Paramyxoviridae, Rhabdoviridae and Reoviridae; iii) two DNA virus families (Herpesviridae and Poxviridae). Compounds 24a, 24b and $24 \mathrm{c}$ resulted moderate activity only against Yellow Fever Virus. Yu et al. (2006) proposed Watersoluble benzimidazol-2-one derivatives with antiviral activity in vivo in the cotton rat model of RSV infection following administration as a small particle aerosol. The acidic compounds 25a, 25b, 25c, 25d, $25 \mathrm{e}$ and $25 \mathrm{f}$ demonstrated potent anti-viral activity in cell culture. Budow et al. (2009) reported a series of benzimidazole derivatives and substituted benzimidazole $\beta$-L- and $\beta$-D-2'-deoxyribonucleosides and evaluated for anti-viral activity against selected RNA and DNA viruses including HIV-1, BVDV, YFV, DENV-2, WNV, HBV, HCV and human RSV.

\section{CONCLUSION}

Benzimidazoles are regarded as a promising class of bioactive heterocyclic compounds that exhibit a range of biological activities like anti-microbial, antiviral, anti-diabetic, and anti-cancer activity. This comprehensive overview summarizes the chemistry of different derivative of substituted benzimidazole along with their anti-microbial activity.

\section{REFERENCES}

Alp, M., Goker, H., Brun, R., Yıldız, S. (2009). Synthesis and anti-parasitic and anti-fungal evaluation of 20- arylsubstituted-1H, 10H-[2, 50] bisbenzimidazolyl-5carboxamidines.Eur.J.Med.Chem. 44:2002-2008. DOI PMid:19010569

Ansari, K.F., Lal, C (2009). Synthesis, physicochemical properties and anti-microbial activity of some new benzi- midazole derivatives. Eur. J. Med. Chem. 44: 4028-4033. DOI PMid:19482384

Budow, S., Kozlowska, M., Gorska, A., Kazimierczuk, Z., Eickmeier, H., Colla, P.L.,Gosselin, G., Seela, F. (2009). Substituted benzimidazoles: anti-viral activity and synthesis of nucleosides. ARKIVOC iii: 225- 250.

Camacho J., Barazarte A., Gamboa N., Rodrigues J., Rojas R., Vaisberg A., Gilman R., Charris J. (2011). Synthesis and biological evaluation of benzimidazole-5-Carbohydrazide derivatives as anti-malarial, cytotoxic and anti-tubercular agents. Bioorg. \& Med. Chem.19: 2023-2029. DOI

Cong, C.,Wang, H., Huc, C., Liu, C., Ma, S., Li, X.,Cao, J., Ma, S. (2011). Synthesis and anti-bacterial activity of novel 400O-benzimidazolyl clarithromycin Derivatives. Eur. J. Med. Chem. 46:3105-3111. DOI PMid:21524827

Cvetkovic, S.O.P.K.D.D. (2011). Lipophilicity and anti-fungal activity of some 2-substituted benzimidazole derivatives. Chem. Ind. \& Chem. Eng. Quart. 17 (1):9-15. DOI

Dandia, A., Singh, R., Merienne, C., Morgant, G., Loupy, A. (2006). Efficient microwave Enhanced regioselective synthesis of a series of benzimidazolyl/triazolyl spiro [indole-thiazolidinones] as potent anti-fungal agents and crystal structure of spiro[3H-indole-3, 20- thiazolidine]30(1, 2,4-triazol-3-yl)- 2,40(1H)-dione. Bioorg. \& Med. Chem. 14: 2409-2417. DOI

Elnima, E.I., Zubair, M., Badar, A.A. (1981). Anti-bacterial and antifungal activities of benzimidazole and benzoxazole derivatives. Antimicrob. Agents Chemother. 19(1):29-32. PMid:7247359 PMCid:181352

Fang, B., Zhou, C.H., Rao, X.C. (2010). Synthesis and biological activities of novel amine-derived bis-azoles as potential anti-bacterial and anti-fungal agents. Eur. J. Med. Chem. 45: 4388-4398. DOI PMid:20598399

Gomez H.T., Nunez E.H., Rivera I.L., Alvarez J.G., Rivera R.C., Puc R.M., Ramos A.R., Gutierrez, M.D.R., Bacab, M.J.C. Vazquez, G.N. (2008). Design, synthesis and in vitro anti-protozoal activity of benzimidazole- pentamidine hybrids. Bioorg. \& Med. Chem. Lett. 18: 3147-3151. DOI

Grocer, H., Kus, C., Boykin, D.W., Yildiz, S., Altanlar, N. (2002). Synthesis and Anti-fungal Properties of Some Benzimidazole Derivatives. Bioorg. Med. Chem.10:25892596. PMid:12057648

Grocer, H., Kus, C., Boykin, D.W., Yildiz, S., Altanlar, N. (2002). Synthesis and Anti-fungal Properties of Some Benzimidazole Derivatives. Bioorg. Med. Chem.10:25892596. PMid:12057648

Gupta, H.C., Jaiswal, V. (2010). Synthesis and Anti-viral Activity of Some New benzimidazoles. J. Ind. Council Chem. 27(2):159-162.

Haugwitz, R.D. (1982). Anti-parasitic agents Synthesis and anti-helmintic activities of novel 2-substituted isothiocyanatobenzoxazoles and benzimidazole. J. Med. Chem. 25: 969-974. DOI PMid:7120286 
Kazimierczuk, Z., Upcroft, J.A., Upcroft, P., Gorska, A., Starosciak, B., Laudy, A. (2002). Synthesis and antiprotozoal activity of some 2-(trifluoromethyl)- $1 \mathrm{H}$ benzimidazole bioisosteres. Acta.Biochim.Pol. 49: 185-195. PMid:12136939

Kilcigil, G.A., Altanlar. (2006). Synthesis and anti-fungal properties of some benzimidazole derivatives. Turk J. Chem. 30:223-228.

Kumar, B.V.S., Vaidya, S.D., Kumar, R.V., Bhirud, S.B., Mane, R.B. (2006). Synthesis and anti-bacterial activity of some novel 2-(6-fluorochroman-2-yl)-1-alkyl/acyl/aroyl-1Hbenzimidazoles. Eur. J. Med. Chem. 41:599-604. DOI PMid:16527375

Kumar, R.V., Vaidya, S.D., Kumar, B.V.S., Bhise, U.N., Bhirud, S.B., Mashelkar, U.C. (2008). Synthesis, antibacterial, anti-asthmatic and anti-diabetic activities of novel N-substituted-2-(4-phenylethynyl-phenyl)-1Hbenzimidazoles and $\mathrm{N}$-substituted 2[4-(4, 4-dimethylthiochroman-6-yl-ethynyl)-phenyl)-1Hbenzimidazoles. Eur. J. Med. Chem. 43:986-995. DOI PMid:17825955

Liu, S., Nelson, A.C., Xiao, L., Lu, L., Seth, P.P., Davis, D.R., Hagedorn, C.H. (2011). Measuring antiviral activity of benzimidazole molecules that alter IRES RNA structure with an infectious hepatitis $C$ virus chimer expressing Renilla luciferase. Anti-viral Res. 89:54-63. DOI PMCid:3018537

Olmo, E.D., Barboza, B., Chiaradia, L.D., Moreno, A., Lerida, J.C., Pacanowska, D.G., Victoria, M., Perez, J.L.L., Giménez, A., Benito, A., Martinez, A.R., Perez, L.M.R.A., Feliciano, A.S. (2011). Anti-malarial activity of imidazo [2, 1- a] isoindol-5-olderivatives and related compounds. Eur. J. Med. Chem. 46:5379- 5386. DOI PMid:21940072

Patil, A., Ganguly, S., Surana, S. (2008). A systemic review of benzimidazole derivatives as an antiulcer agent. Rasayan Journal of Chemistry, 1(3): 447-460.

Ryckebusch A., Fontaine M.A.D., Mouray E., Grellier P., Sergheraerta C., Melnyk P. (2005). Synthesis and antimalarial evaluation of new N1-(7-chloro-4-quinolyl)-1, 4bis (3-aminopropyl)-piperazine derivatives. Bioorg. \& Med. Chem. Lett.15: 297-302. DOI

Sharma, S., Gangal, S., Rauf, A. (2009). Convenient one-pot synthesis of novel 2-substituted benzimidazoles, tetrahydrobenzimidazoles and imidazoles and evaluation of their in vitro antibacterial and antifungal activities. Eur. J.Med.Chem. 44:1751-1757. DOI PMid:18472189
Starcevic, K., Kralj, M, Ester, K., Sabol, I., Grce, M., Pavelic, K., Zamola, G.K. (2007). Synthesis, anti-viral and antitumor activity of 2-substituted-5-amidino-benzimidazoles. Bioorg. \& Med. Chem.15:4419-4426. DOI

Tuncbilek, M., Kiper T., Altanlar, N. (2009). Synthesis and in vitro anti-microbial activity of some novel substituted benzimidazole derivatives having potent activity against MRSA. Eur. J. Med. Chem. 44:1024-1033. DOI PMid:18718694

Vazquez, G.N, Vilchis, M.D.M.R., Mulia, L.Y., Meléndez, V., Gerena, L., Campos, A.H., Castillo, R., Lui, F.H. (2006). Synthesis and anti-protozoal activity of some 2(trifluoromethyl)-1H- benzimidazole bioisosteres. Eur. J. Med. Chem. 41: 135-141. PMid:16260067

Vitale, G., Carta, A., Loriga, M., Paglietti, G., Colla, P., Busonera, B., Collu, D., Loddo, R. (2008). 2Arylbenzimidazoles as Anti-viral and Anti-proliferative Agents-Part 1. Med. Chem. 4:605-615. DOI PMid:18991746

Yadav, S., Kumar, P., Clercq, E.D., Balzarini, J., Pannecouque, C., Dewan, S.K., Narasimhan, B. (2010). 4-[1-(Substituted aryl/alkyl carbonyl)-benzoimidazol-2-yl]-benzenesulfonic acids: Synthesis, anti-microbial activity, QSAR studies, and anti-viral evaluation. Eur. J. Med. Chem. 45:5985-5997. DOI PMid:20971531

Yu, K.U., Wang, X.A., Civiello, R.L., Trehan, A.K., Pearce, B.C., Yin, Z., Combrink, K.D., Gulgeze, H.B., Zhang, Y., Kadow, K.F., Cianci, C.W., Clarke, J., Genovesi, E.V., Medina, I., Lamb, L., Wyde, P.R., Krystal, M., Meanwell, N.A. (2006). Respiratory syncytial virus fusion inhibitors. Part 3: Water-solub benzimidazol-2-one derivatives with anti-viral activity in vivo. Bioorg. \& Med. Chem. Lett. 16:1115-1122. DOI

Zhang, D., Wang, Z., Xu, W., Sun, F., Tang, L., Wang, J. (2009). Design, synthesis and anti-bacterial activity of novel actinonin derivatives containing benzimidazole heterocycles. Eur. J. Med.Chem. 44:2202- 2210. DOI PMid:18617291 